\title{
A Handbook of Parenteral Nutrition
}

Hospital and home applications 


\section{A Handbook of}

Parenteral Nutrition

Hospital and home applications

Edited by

H.A. Lee and G. Venkat Raman

(1)

SPRINGER-SCIENCE+BUSINESS MEDIA, B.V. 
First edition

(C) 1990 Lee and Raman

Originally published by Chapman and Hall in 1990

Typeset in 10/12pt Palacio by Mayhew Typesetting, Bristol

Bury St Edmunds, Suffolk

ISBN 978-0-412-28030-6

All rights reserved. No part of this publication may be reproduced or transmitted, in any form or by any means, electronic, mechanical, photocopying, recording or otherwise, or stored in any retrieval system of any nature, without the written permission of the copyright holder and the publisher, application for which shall be made to the publisher.

British Library Cataloguing in Publication Data

A Handbook of parenteral nutrition.

1. Medicine. Parenteral feeding

I. Lee, H.A. (Harry Andre) II. Raman G.V. (G. Venkat) $615.8^{\prime} 5$

ISBN 978-0-412-28030-6 ISBN 978-1-4899-3464-2 (eBook)

DOI 10.1007/978-1-4899-3464-2

\section{Library of Congress Cataloging-in-Publication Data}

A Handbook of parenteral nutrition : hospital and home applications / edited by H.A. Lee and G.V. Raman. p. $\mathrm{cm}$.

Includes bibliographical references.

ISBN 978-0-412-28030-6

1. Parenteral feeding - Handbooks, manuals, etc. I. Lee, H.A. (Harry André) II. Raman, G.V. (G. Venkat)

[DNLM: 1. Parenteral Feeding. WB 410 H236]

RM224.H26 1990

$615.8^{\prime} 55$ - dc20

DNLM/DLC

for Library of Congress 
To our wives Gilly and Kumkum 


\section{Contents}

Contributors $\quad$ ix

Preface $\quad$ xi

1. History of parenteral nutrition 1

H.A. LEE

2. General principles of parenteral nutrition 7 G. VENKAT RAMAN

3. Vascular access 52

G. VENKAT RAMAN

4. Paediatric aspects of parenteral nutrition

A.H.B. FYFE AND F. COCKBURN

5. Organization of parenteral nutrition in hospital and at home H.A. LEE

6. Patient training and nursing aspects J. COLLETT

7. Practical aspects of patient monitoring during intravenous feeding H.A. LEE

8. Complications of parenteral nutrition G. VENKAT RAMAN

9. Prognosis and outcome

H.A. LEE AND G. VENKAT RAMAN

Suggested reading

Glossary of available products 168

Vascular catheters for parenteral nutrition $\quad 170$

Index 


\section{Contributors}

F. COCKBURN, MD, FRCP (EDIN. and GLAS), DCH

Professor of Child Health, University of Glasgow

Consultant Paediatrician, Royal Hospital for Sick Children and Queen Mother's Hospital, Glasgow, UK

\section{J. COLLETT, SRN}

Clinical Nurse Specialist in Nutrition

Portsmouth and South East Hants Health Authority

St Mary's Hospital, Portsmouth, Hampshire, UK

A.H.B. FYFE, MBChB, FRCS (GLAS)

Consultant Paediatric Surgeon

Royal Hospital for Sick Children, Glasgow, UK

\section{H.A. LEE, BSc, MBBS, FRCP, MRCS}

Professor of Renal Medicine, University of Southampton

Director of the Wessex Regional Renal and Transplant Unit

Consultant Physician to the Portsmouth and S.E. Hants

Health Authority

Titular Head of the Infectious Diseases Unit

St Mary's Hospital, Portsmouth, Hampshire, UK

G. VENKAT RAMAN, MD, MBBS, MRCP (UK), MNAMS (INDIA)

Consultant Nephrologist to the Wessex Regional Renal and Transplant Unit

Senior Lecturer in Renal Medicine, University of Southampton

Consultant Physician to the Portsmouth and S.E. Hants Health Authority

Consultant Physician to the Infectious Diseases Unit St Mary's Hospital, Portsmouth, Hampshire, UK 


\section{Preface}

Total parenteral nutrition (TPN) is now an everyday occurrence in most general hospitals. Over the last two decades this therapeutic modality has been made so simple that it is no longer the province of the specialized surgeon or physician. Indeed, as with the management of chronic renal failure so now with short bowel disease, home parenteral nutrition has become a reality, though this still requires a specialist team dedicated to its management.

Furthermore, as more patients will become suitable for home TPN treatment (either long term or short term) so better rationalization of (a) cost, (b) delivery systems and (c) patient training will be necessary. Lessons can be learnt from the somewhat diverse development of regular dialysis treatment in the early 1960s compared with the situation today. Here is a golden opportunity, with the UK National Registry, to rationalize on home TPN costs and to make sure the treatment is simplified and available to all those who may require this treatment.

This book is not designed to be an overall comprehensive review of parenteral nutrition. It is meant to set out simple guidelines and the requirements for effective TPN both in hospital and at home. It is aimed at doctors in training, interested physicians and surgeons, nurses, dietitians and pharmacists. The purpose is to stimulate interest and awareness, rather than to provide detailed 'small-print' information. For the person seeking greater knowledge, there are several excellent monographs on the subject.

The book sets out the historical background to the development of TPN, its use in hospital practice and its application (by self-care) in the home environment. This latter aspect, in particular, has been helped by the creation of the nurse specialist in nutritional support in many hospitals. In our own 
district, in common with many others, the nutritional support team is multidisciplinary and provides advice on the biochemical, pharmaceutical, medical, nursing and psychosocial aspects of nutritional support (both enteral and parenteral), either in hospital or in the home.

It is the hope of the authors that this small volume will emphasize the relative simplicity of this treatment and broaden the indications for its application. We also hope that this book will help to influence respective sources of finance (the government in the case of this country), to provide adequate funding that is required for successful home TPN. There should be no question of any financial pressures being brought to bear upon the families of patients requiring TPN. It is the view of the editors that this therapeutic modality, particularly in the home environment, will increase and hopefully gain recognition from the government for central funding.

The editors would like to thank their contributors for their valuable contributions; without their cooperative assistance this volume would not have been complete, nor would it have the same degree of credibility. We are also grateful for the patient forbearance of our secretaries Mrs June Donovan, Mrs Susan Morris and Miss Heather Morton, who were instrumental in preparing the original manuscripts and the (many) subsequent re-editions. We are grateful to the nursing, dietetic and pharmacy staff, who have contributed so much to the formation and function of our Nutritional Support Team. We would like to thank Professor Miles Irving of Hope Hospital, Salford for providing free access to the information from the UK TPN Registry and Dr Alan Shenkin, Consultant Clinical Biochemist, of Glasgow Royal Infirmary for numerous trace element estimations and valuable clinical advice. Finally, we are indebted to all the patients who have undergone great suffering, with fortitude and courage, and taught us a great deal more than just medicine.

H.A. LEE

G. VENKAT RAMAN 